\title{
Discrete finite element model of reactive powder concrete columns confined with fiber reinforced polymer
}

\author{
M. Abbassi' ${ }^{1}$ H. Dabbagh ${ }^{1}$ \\ ${ }^{1}$ Department of Civil Engineering, Faculty of Engineering, University of Kurdistan, Sanandaj, Iran \\ Phone: +988716660073; Fax: +988716668513
}

ABSTRACT - Numerous finite element methods have been widely used to predict the response of normal/high strength concrete columns confined with Fiber Reinforced Polymer (FRP) under different loading conditions. In this regard, simulating the response of FRP-confined reactive powder concrete (RPC) columns has been less emphasized. The present study aimed to propose a finite element model based on fiber finite element methodology in order to predict the behavior of FRP confined RPC columns under axial compressive load with different eccentricities. The columns were modeled with a nonlinear beam-column element with two nodes with distributed plasticity. In addition, the proposed finite element model in the present study indicated its simplicity, low computational efforts, and flexibility by adopting a perfect bond between RPC and FRP. Further, the obtained results from the finite element analysis were compared to those from available tested specimens. Based on the comparisons, the proposed model can provide highly satisfactory predictions. Finally, the proposed model can be useful for efficient applications in practical engineering projects.

\author{
ARTICLE HISTORY \\ Received: $29^{\text {th }}$ June 2019 \\ Revised: $26^{\text {th }}$ Jan 2021 \\ Accepted: $28^{\text {th }}$ Mar 2021

\section{KEYWORDS} \\ Finite element analysis; \\ reactive powder \\ concrete columns; \\ FRP wrapping; \\ discrete finite element \\ model; \\ compressive load
}

\section{INTRODUCTION}

During the past three decades, Fiber Reinforced Polymer (FRP) composites such as Carbon-FRP and Glass-FRP have attracted a lot of attention for wide applications in civil engineering, especially in retrofitting and strengthening concrete members due to their high strength-to-weight ratio, ease of application, and high corrosion resistance. A large number of studies reported that external confinement through FRP wrapping can increase the strength and ductility of concrete columns [1-3]. In addition, the use of FRPs confinement led to satisfactory performance, especially in earthquakes prone areas [4-5]. In this context, one area that may be of interest to researchers and engineers is the use of FRP to confine reactive powder concrete (RPC) columns. Reactive powder concrete is considered as one new type of cement-based composite material, which was invented in the early 1990s by Bouvgues laboratory in France [6-7]. Further, RPC has ultra-high compressive strength, limited shrinkage, and high toughness [8-9]. The size of columns for newer high-rise buildings can be normally reduced by taking the advantage of the ultra-high compressive strength of RPC. Thus, more space should be obtained to use and rent [10]. Additionally, one of the topics that could be of interest in this area is that the use of FRP in RPC columns might increase the ductility and strength of RPC columns which are especially important for satisfactory structural performance in the multistory structures.

In addition, the constitutive model of RPC, especially the stiffness and compressive strength of RPC can change due to FRP confinement. Designing FRP-confined RPC columns properly to get acceptable and reasonable response requires an accurate estimation of the structural behavior. Based on numerical approach, a large number of researchers have proposed different finite element models to predict the response of FRP-confined concrete columns [11-13]. Wrapping, simulating, and evaluating the mechanical response of reactive powder concrete columns confined with fiber reinforced polymer are considered as a challenging issues although a large number of studies have been conducted to model the response of normal/high strength concrete columns confined with FRP [11-13].

Based on the above literature, most of the previous finite element models [11-13] employed constitutive models based on plasticity theory, especially Drucker-Prager type plasticity models. In addition to the accuracy of a constitutive model to describe the behavior of confined concrete, the material parameters of the model should be easily obtained [14]. In order to use plasticity methodology to nonlinear analysis, several distinct components such as yield criterion, hardening/softening rule, and flow rule are necessary for defining the realistic behavior of confined concrete correctly. Given this, many of the components needed to predict the behavior of reactive powder concrete based on the plasticity theory have not been accurately determined. Further, the use of those finite element models to predict the response of FRP-confined concrete columns in common professional practice has not been completely extended, due to the difficulty in the theoretical background for practical engineers or the complexity of the involved material models.

Furthermore, the implementation of the numerical model for the nonlinear finite element analyses of confined concrete columns should be practical and numerically efficient. However, most of the previous models have focused on microscopic finite element models to simulate the behavior of FRP-confined normal-strength concrete columns. The 
microscopic finite element (FE) models are highly expensive because of time-consuming and complex tasks involved in the analysis although the finite element method offers a powerful tool for simulating the nonlinear behavior of confined concrete columns according to the microscopic approach [14]. In addition, microscopic finite element models might be appropriate for the detailed study of critical regions of the structures or situations such as creep, relaxation, and geometric crack discontinuities [15]. Therefore, proposing new models for simplifying and reducing the computational effort with proper accuracy of the whole process of nonlinear analysis of confined concrete columns have been emphasized during recent years.

Regarding the above shortcomings, the present study aimed to propose a finite element model in order to simulate the behavior of circular reactive powder concrete columns confined with Fiber Reinforced Polymer (FRP). In the present study, the columns were exposed to axial compressive load with different eccentricities. The model is based on discrete finite element modeling methodology. The columns are modeled with a two-noded nonlinear beam-column element with distributed plasticity. The proposed model has appropriate accuracy, low computational efforts and flexibility, along with simplicity, which is useful for practical engineers. A comparison study was conducted to find out a simple constitutive model which predicts stress-strain response of RPC, compared to appropriate accuracy. Finally, a comparison of axial load-axial strain and axial load-lateral displacement response of the proposed model with the available test data was presented for the reliable evaluation of the performance of the proposed finite element model.

\section{NUMERICAL SIMULATION OF CONFINED RPC COLUMNS}

This section gives a brief overview of the proposed model and modeling process. For simplicity, the following assumptions are adopted in the present study:

1. The described modeling approach is originally developed for FRP wrapping confined RPC columns having circular cross sections.

2. Perfect bond is assumed between the concrete and FRP in order to neglect the slippage of FRP wrapping.

3. Geometric interaction between the FRP wrapping and the reactive powder concrete is ignored in the modeling.

4. The external loading conditions are simulated with an axial load and a flexural moment on the column centerline.

5. All loads are always applied by nodal forces and moments.

6. The norm displacement increment is considered to be $1 \mathrm{e}-5$ for the evaluation of convergence.

\section{Element Type and Modeling Strategy}

Basically, selecting a characteristic finite element model, analyzing the model, and interpreting the results are considered as the finite element analyses. Although selecting an appropriate finite element model and interpreting the results are crucial in engineering practice, a reliable and accurate response prediction with low computational cost and effort of the model is essential so that the analysis results can be used with confidence [16]. In this regard, although numerical analysis of FRP confined concrete columns by means of solid elements has been mostly employed in previous studies, it becomes too expensive and tedious in the computational sense, especially when it is applied for nonlinear analysis of structures with nonlinear behavior. On the other hand, very simple assumptions is proposed in this study to perform nonlinear finite element analyses although three-dimensional solid elements can be assumed for predicting the behavior of the FRP confined RPC columns. In the present study, two-nodded nonlinear beam-column element was used by enforcing Bernoulli beam assumptions to model the FRP confined RPC columns. The nonlinear beam-column element has nonlinearity distribution and three degrees of freedom at each node. In addition, the proposed finite element model considered the FRP confined RPC columns replaced at its centroid axis by the nonlinear beam-column element. The proposed model for the axial eccentrically loaded FRP confined RPC columns includes three nodes and two elements. The number of nodes for concentrically loaded FRP confined RPC columns is two and the number of elements is one. Figure 1 illustrates the typical models for the analysis.

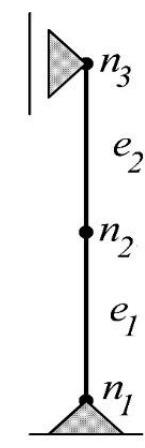

(a)

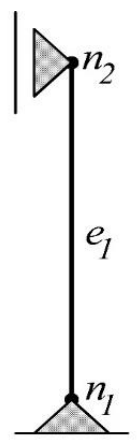

(b)

Figure 1. Typical models for (a) eccentrically loaded columns and (b) concentrically loaded columns 
It is worth noting that discrete finite element modeling strategy is used to simulate the behavior of the FRP confined RPC columns (Figure 2). In order to model based on this methodology, the cross section of the used nonlinear beamcolumn element is divided into two reactive powder concrete and fiber reinforced polymer. Each part is discretized into several discrete smaller cross-section regions called "fibers". The stress-strain model of FRP and RPC is required to describe their behaviors as it was discussed in next section (material modeling). Equation (1) is used to compute the section resisting forces by the summation of the axial force and bending moment contribution of all the fibers [17].

$$
D(x)=\left\{\begin{array}{c}
M_{y}(x) \\
N(x)
\end{array}\right\}=\left\{\begin{array}{c}
\sum_{i f i b=1}^{n} \sigma_{i f i b} \cdot A_{i f i b} \cdot Z_{i f i b} \\
\sum_{i f i b=1}^{n} \sigma_{i f i b} \cdot A_{i f i b}
\end{array}\right\}
$$

Where $n$ represents the number of fiber sections, $x$ denotes the longitudinal axis of the member, $\sigma$ is the normal stress, and $A_{i f i b}$ is the area of $i-t h$ fiber. $D(x)$ is regarded as the resisting section force including the axial force $N(x)$, bending moment $M_{y}(x)$ at section $x$, and $Z_{i f i b}$ refers to the fiber position in the cross section. Figure 2 displays the typical discrete finite elements model used in this paper.

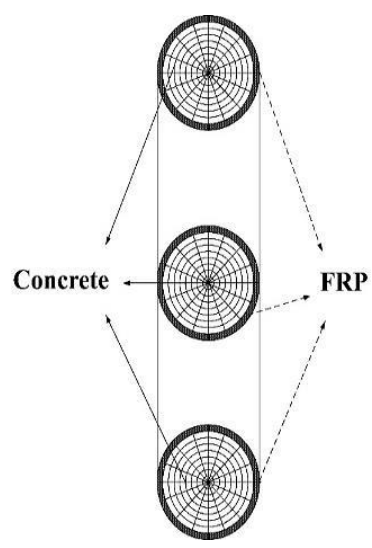

Figure 2. Schematic of the partition of monitored cross-sections of FRP-confined RPC columns

The recorded data for post-processing the considered confined columns included mid-height lateral displacement, axial compression strain for column head, and axial force at end nodes. Shear effects are not included in the analysis, which is an acceptable approximation for medium to large span to depth ratios of the member when the response of this particular column is dominated by flexure and axial load [15, 18].

\section{Material Modeling}

The accuracy and reliability of the finite element analysis are largely dependent on material constitutive models [19]. In the present study, the constitutive stress-strain models of FRP and RPC govern the response of FRP confined RPC columns. Several parameters influence the response of concrete columns confined with FRP wrapping. In this regard, although many constitutive stress-strain models can be assumed for describing the behavior of the materials, simple material models were adopted to facilitate the modeling process which could avoid many of the mathematics and large parameters. In addition, the model should provide a satisfactory prediction of stress-strain curve of the materials. Since perfect bond is assumed between the RPC and FRP, two material models including FRP and RPC constitutive models are needed for the modeling process. Obviously, reactive powder concrete shows different stress-strain behaviors in compression and tension. RPC behavior in uniaxial comkpression consists of hardening and softening branches. In this context, a number of expressions were proposed for describing the complete compressive stress-strain relationship of normal and high strength concrete. However, the stress-strain behavior of RPC has been less emphasized, and no stressstrain relationship was presented for describing the behavior of reactive powder concrete. In order to determine a stressstrain model which reflects the behavior of RPC better under uniaxial compression, six stress-strain models suggested by Bach [20], Desay and Krishnan [21], Carreira and Chu [22], Kent and Park [23], Smith and Young [24] and Todeschini et al. [25] were reviewed. Further, in order to evaluate the performance of the considered six models, a comparison study was performed to find out a constitutive model which could accurately predict the stress-strain response of RPC under uniaxial compressive load included in the experimental database [26-29]. Figures 3-6 illustrates the comparisons of results of the six stress-strain models and experimental results. 


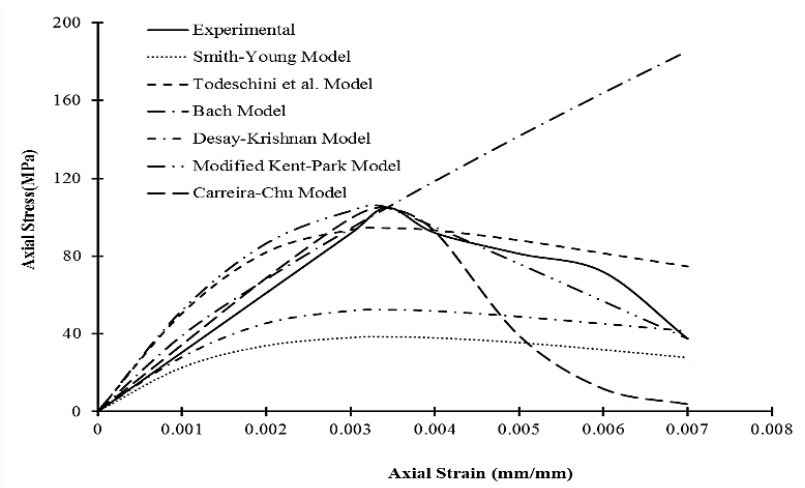

Figure 3. Comparison of experimental results [26] and numerical models results

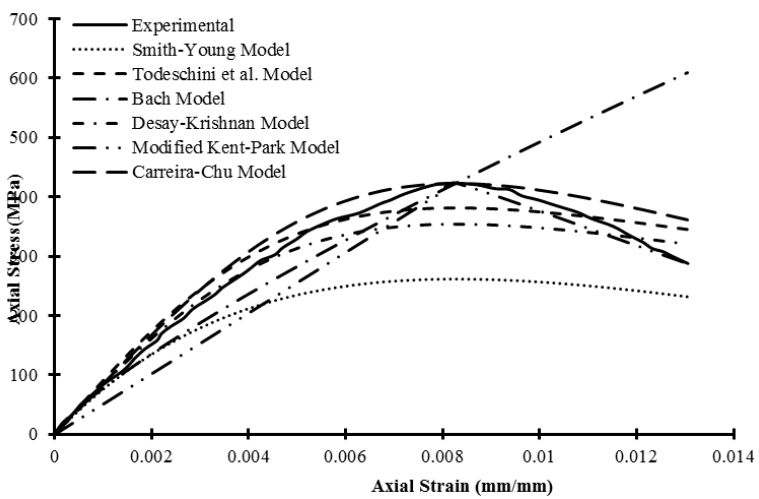

Figure 4. Comparison of experimental results [27] and numerical models results

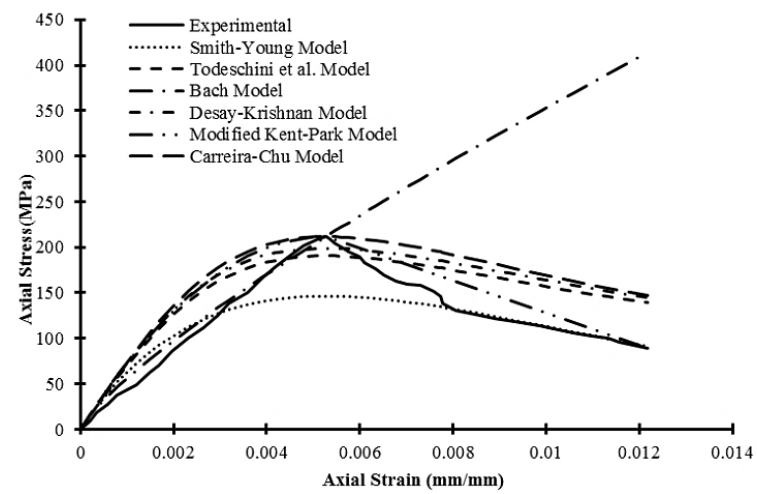

Figure 5. Comparison of experimental results [28] and numerical models results

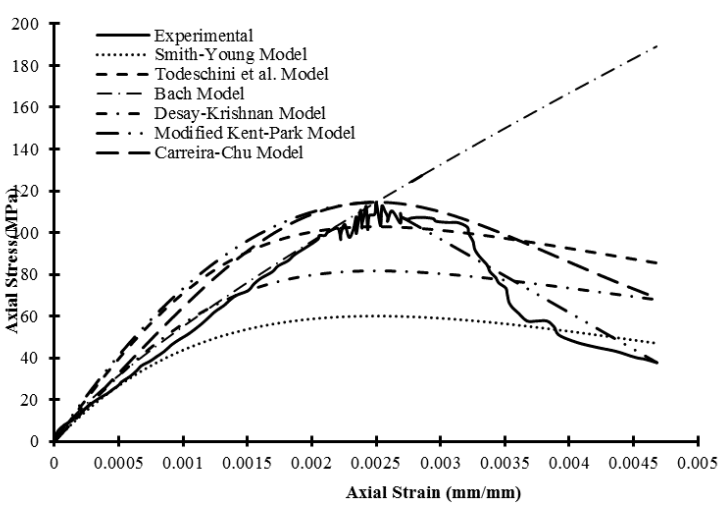

Figure 6. Comparison of experimental results [29] and numerical models results 
As shown, the modified Kent and Park model could properly predict the complete stress-strain behavior of RPC in compression allowing for a wide range of RPC characteristics. Furthermore, the so called modified Kent and Park model can present an adequate balance between simplicity and accuracy to predict the stress-strain response of RPC in compression although more accurate and complex constitutive models are available [30-31]. Hence, modified Kent and Park model is preferred for the numerical approximation of the stress-strain response of RPC. Based on modified Kent and Park model, the monotonic stress-strain relations of concrete in compression are defined in parabolic ascending stress, linear descending, and constant residual stress regions (Figure 7).

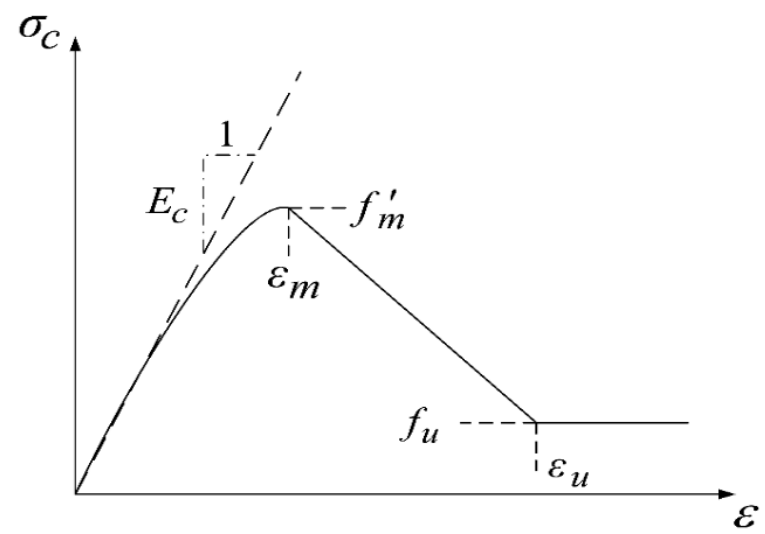

Figure 7. Schematic of constitutive model of concrete in compression according to modified Kent-Park model

Like the constitutive stress-strain model adopted for RPC in compression, a constitutive model is necessary for describing the stress-strain behavior of RPC in tension. Based on a number of tests and studies for concrete [32-34], the constitutive model which is preferred for simulating the stress-strain behavior of reactive powder concrete in tension includes an ascending linear elastic portion up to the tensile strength $f_{t}^{\prime}$, and a descending linear portion which accounts for the tension stiffening occurs after this point. Figure 8 displays the typical stress-strain behavior of reactive powder concrete in tension.

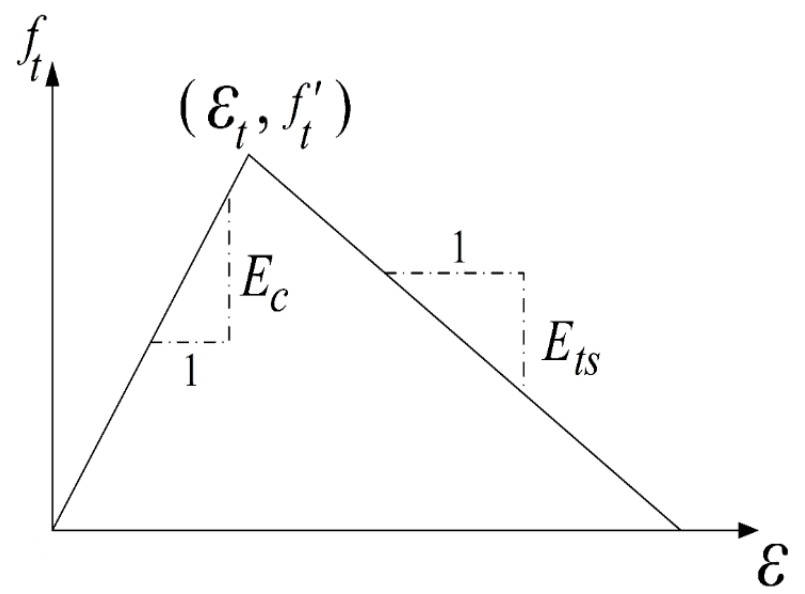

Figure 8. Schematic of concrete constitutive model in tension

Regarding FRP, it is assumed that the FRP constitutive model in tension and compression is considered as a linear elastic and brittle model. Further, FRP encompasses the same elastic modulus in tension and compression [35]. The typical stress-strain behavior of FRP is plotted in Figure 9. 


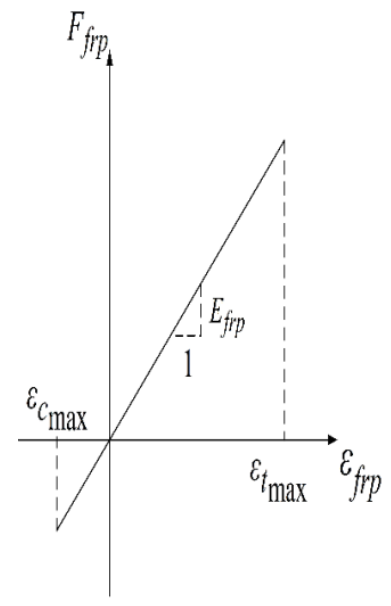

Figure 9. FRP constitutive model

\section{NUMERICAL SOLUTION PROCEDURE}

The selection of an appropriate solution procedure is crucial because the difficulty and cost of analysis heavily relies on the selected solution procedure. Although Newton-Raphson iteration is the most frequently used iteration scheme [36], this process can be computationally expensive and time-demanding, due to the decomposing of the tangential stiffness matrix at each iteration and the solution of a set of linear equations. Thus, the modified Newton-Raphson iteration was preferred for analyzing confined RPC columns in the present study. Saving computer time is regarded as the main advantage of the modified Newton-Raphson method. Further, in this study, the open system for earthquake engineering simulation software (OpenSees) was employed to simulate the response of FRP confined RPC columns. OpenSees software framework is based on object-oriented methodologies and was developed by the pacific earthquake engineering research center at the University of California, Berkeley [37].

\section{RESULTS AND DISCUSSIONS}

In general, the finite element results should be presented to demonstrate the applicability and accuracy of the proposed model. In order to verify the accuracy of the proposed model, FRP confined RPC columns tested by Malik and Foster [38] are numerically modeled. The columns were cast with reactive powder concrete including either steel fibers or without these fibers. The concrete column specimens wrapped with either two types of fiber reinforced by polymer wrapping. Tables 1 and 2 present the details for the FRP type used for wrapping the columns and FRP properties, respectively.

Table 1. Details of FRP type wrapping [38]

\begin{tabular}{lllll}
\hline Laminate & Wrap Type 1 & & Wrap Type 2 & \\
\cline { 2 - 5 } Structure & Fiber Sheet & Wrap direction & Fiber Sheet & Wrap direction \\
Layer1 & CF120 & Longitudinal & CF350 & Longitudinal \\
Layer2 & CF120 & Longitudinal & CF350 & Longitudinal \\
Layer3 & CF120 & Circumferential & CF120 & Circumferential \\
Layer4 & CF120 & Circumferential & CF120 & Circumferential \\
\hline
\end{tabular}

Table 2. Mechanical properties of FRP [38]

\begin{tabular}{lll}
\hline FRP Type & CF120 & CF350 \\
\hline Tensile strength, f_(t_frp) $\wedge^{\wedge}$ & $3800 \mathrm{MPA}$ & $2650 \mathrm{MPA}$ \\
Modulus of Elasticity & $240 \mathrm{GPA}$ & $640 \mathrm{GPA}$ \\
Ultimate strain & $1.55 \%$ & $0.4 \%$ \\
Thickness & $0.117 \mathrm{~mm}$ & $0.19 \mathrm{~mm}$ \\
\hline
\end{tabular}


The confined RPC columns were tested under axial compressive load with different eccentricities. Details of the column specimens are presented in Table 3.

Table 3. Material properties of RPC and column details [38-39]

\begin{tabular}{cccccccc}
\hline Specimens & $\rho(\%)$ & $f_{m}^{\prime}(\mathrm{MPA})$ & $f_{t}^{\prime}(\mathrm{MPA})$ & $\mathrm{E}(\mathrm{mm})$ & $\mathrm{D}(\mathrm{mm})$ & $\mathrm{H}(\mathrm{mm})$ & Wrap type \\
\hline FC0 & 2 & 165 & 7.7 & 0.0 & 152.3 & 1048 & - \\
FC0-1 & 2 & 168 & 7.9 & 0.0 & 152.3 & 1055 & 1 \\
FC0-2 & 2 & 168 & 7.9 & 0.0 & 152.5 & 1060 & 1 \\
FC10-1 & 2 & 165 & 7.7 & 10 & 152.2 & 1060 & 1 \\
FC10-2 & 2 & 172 & 7.6 & 10 & 152.3 & 1060 & 2 \\
FC20-1 & 2 & 163 & 8.2 & 20 & 152.5 & 1056 & 1 \\
FC20-2 & 2 & 165 & 7.7 & 20 & 152.3 & 1056 & 2 \\
FC35-1 & 2 & 165 & 7.7 & 35 & 152.4 & 1058 & 1 \\
FC35-2 & 2 & 168 & 8.7 & 35 & 152.2 & 1060 & 2 \\
PC0-1 & 0.0 & 145 & 3 & 0.0 & 152.6 & 1054 & 1 \\
PC0-2 & 0.0 & 145 & 3 & 0.0 & 152.3 & 1055 & 1 \\
PC10-1 & 0.0 & 139 & 3.1 & 10 & 152 & 1055 & 1 \\
PC20-1 & 0.0 & 139 & 3.1 & 20 & 152.7 & 1054 & 1 \\
PC35-1 & 0.0 & 143 & 3.3 & 35 & 152.4 & 1055 & 1 \\
\hline
\end{tabular}

Where $\rho$ represents the volumetric percentage of steel fibers, $f_{m}^{\prime}$ indicates the compressive strength of RPC, $e$ shows the eccentricity of the load, $D, \mathrm{H}$, and $f_{t}^{\prime}$ are regarded as the diameter of concrete column cross-section, the height of the columns, and the tensile strength of RPC, respectively.

The thickness of the fiber sheets was 0.117 and $0.19 \mathrm{~mm}$ for CF120 and CF530, respectively. The following objects were incorporated in the finite element modeling:

1. Concrete input properties include concrete compressive strength $\left(f_{m}^{\prime}\right)$, concrete strain at compressive strength $\left(\varepsilon_{m}\right)$, concrete crushing strength $\left(f_{u}\right)$, concrete strain at crushing strength $\left(\varepsilon_{u}\right)$, concrete tensile strength $\left(f_{t}^{\prime}\right)$, and concrete tension softening stiffness (Ets) (Figures 7-8).

2. The input properties assigned to FRP consisted of the modulus of elasticity $\left(E_{f r p}\right)$, strain at tensile strength $\left(\varepsilon_{t_{\max }}\right)$, and strain at compressive strength $\left(\varepsilon_{c_{\max }}\right)$ (Figure 9$)$.

Figures 10-14 display the comparison of nonlinear FE analysis results, along with experimental test results of the axial load-axial compression strain curve for specimens under concentric loading.

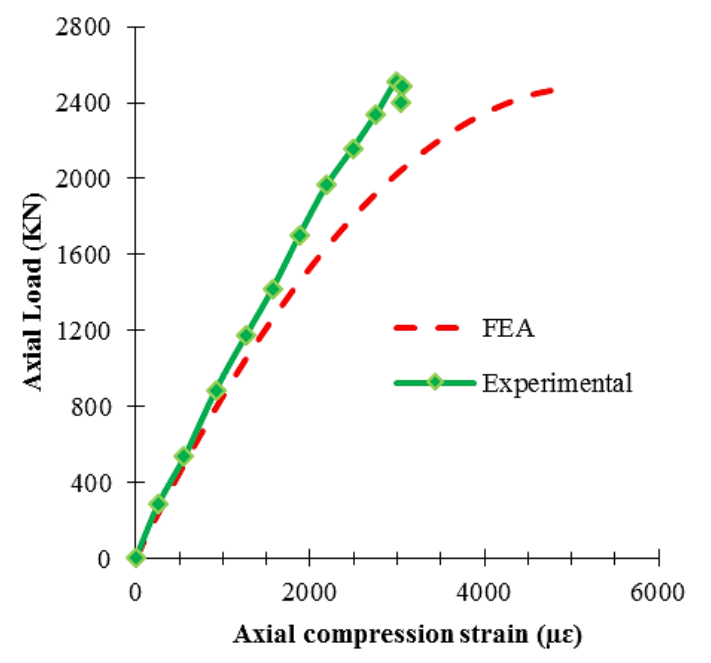

Figure 10. Comparison of predicted result with test data for the column FC0 


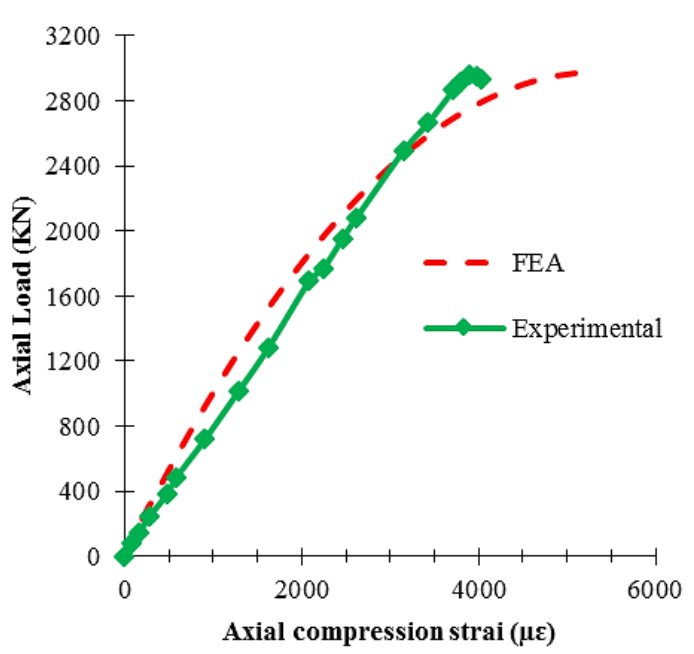

Figure 11. Comparison of predicted result with test data for the column $\mathrm{FC} 0-1$

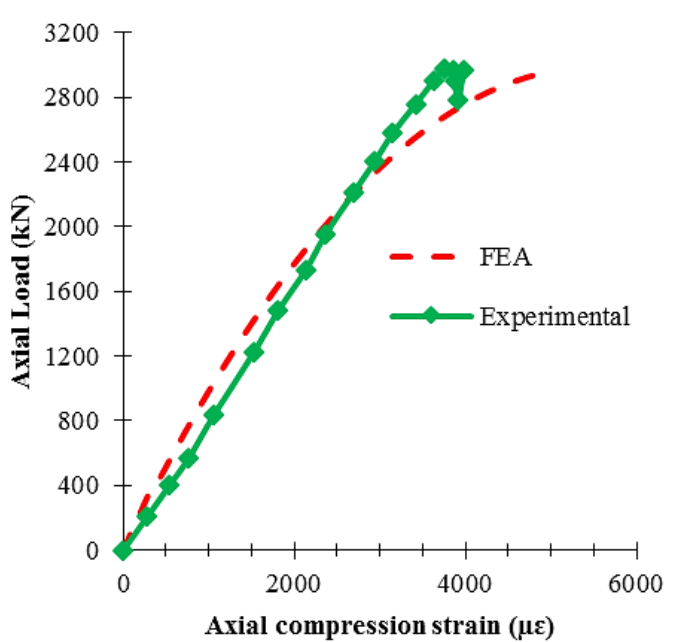

Figure 12. Comparison of predicted result with test data for the column FC0-2

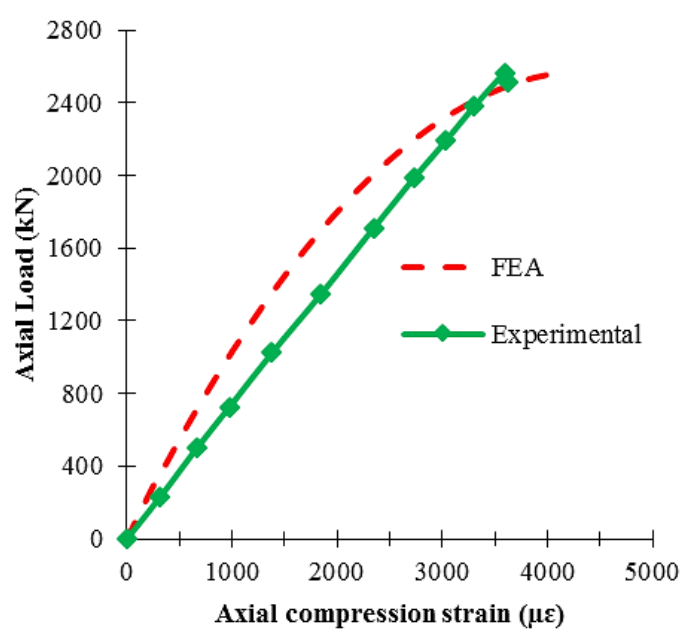

Figure 13. Comparison of predicted result with test data for the column PC0-1 


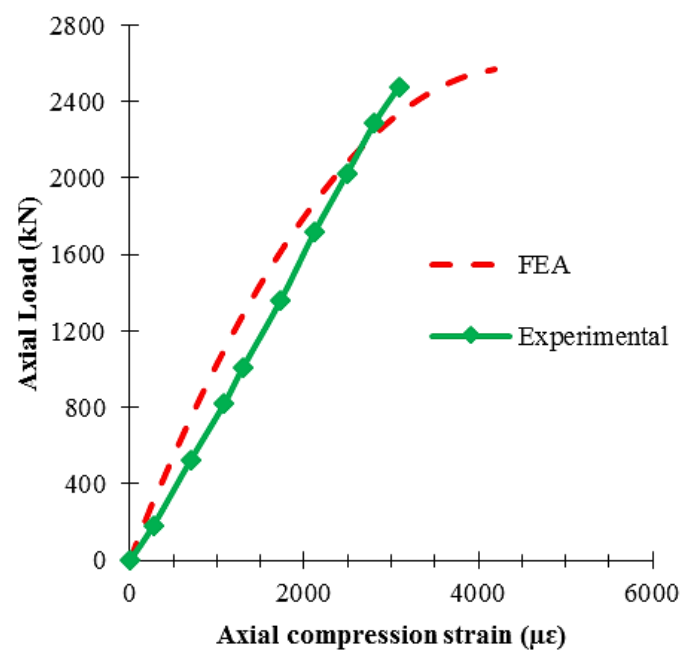

Figure 14. Comparison of predicted result with test data for the column PC0-2

The curves demonstrated that FE analysis results could accurately predict the response of experimental tests for the confined RPC columns exposed to concentric loading. As illustrated in Figures 10-14, FE analysis results could accurately predict the maximum load and maximum compression strain for the concentric loaded RPC columns. In addition, reasonable agreement was found with respect to the initial slope of the axial load-axial compression strain curve.

Figures 15-23 display the comparisons in terms of axial load-mid height lateral displacement curves obtained from the finite element analysis results of specimens under eccentric loading to those obtained in the laboratory tests.

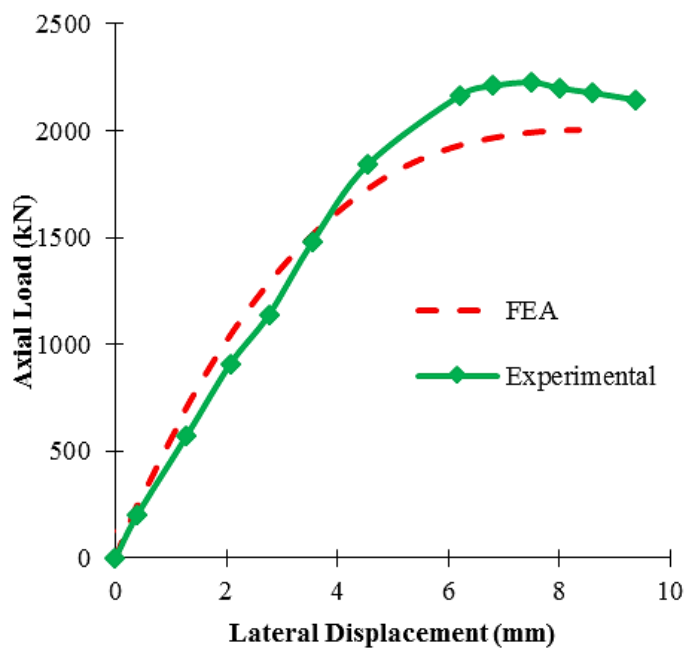

Figure 15. Comparison of predicted result with test data for the column FC10-1

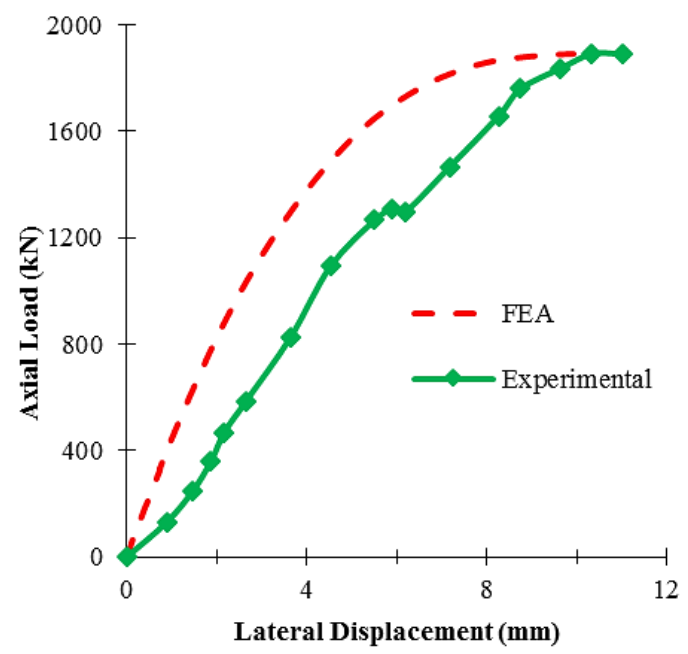

Figure 16. Comparison of predicted result with test data for the column FC10-2 


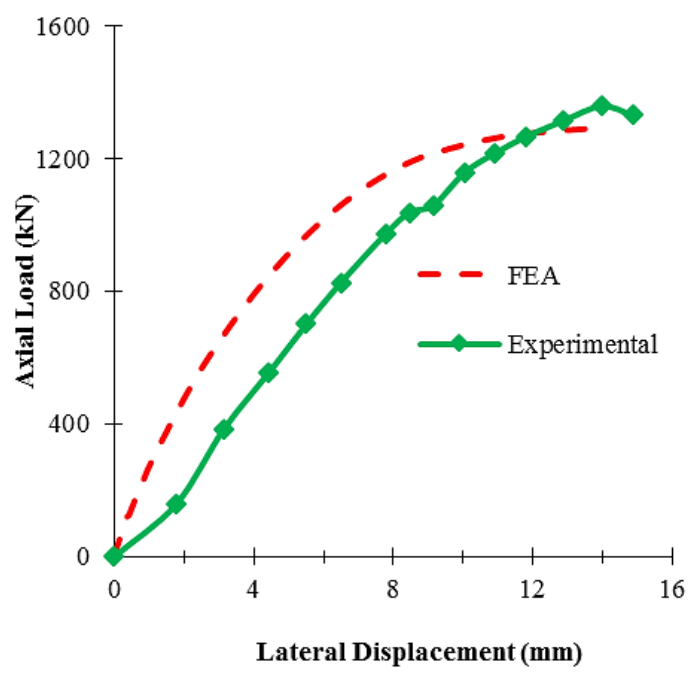

Figure 17. Comparison of predicted result with test data for the column FC20-1

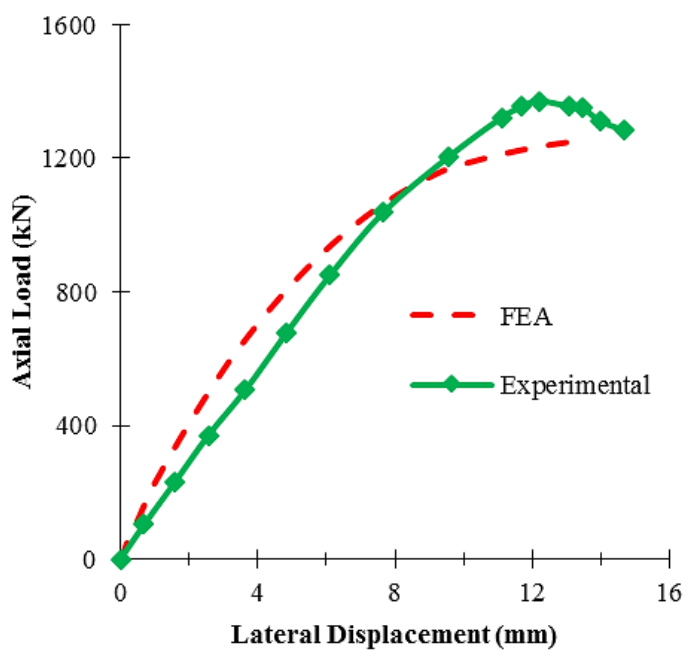

Figure 18. Comparison of predicted result with test data for the column FC20-2

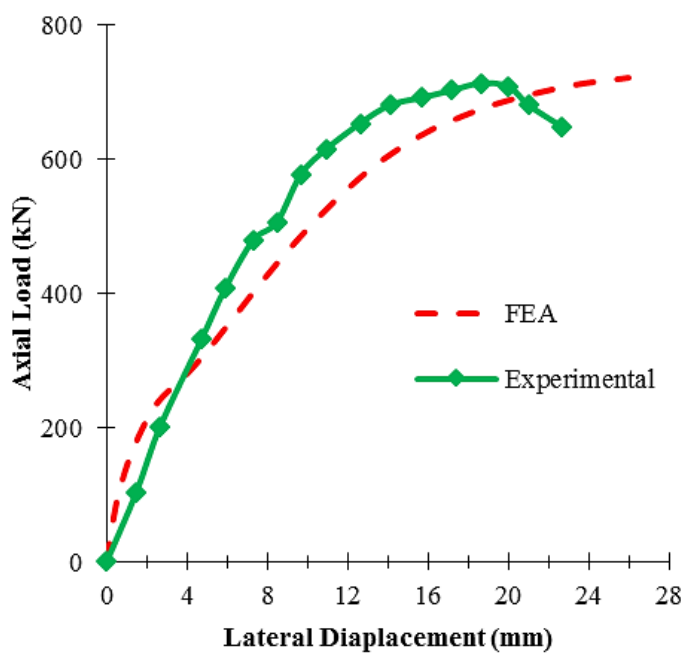

Figure 19. Comparison of predicted result with test data for the column FC35-1 


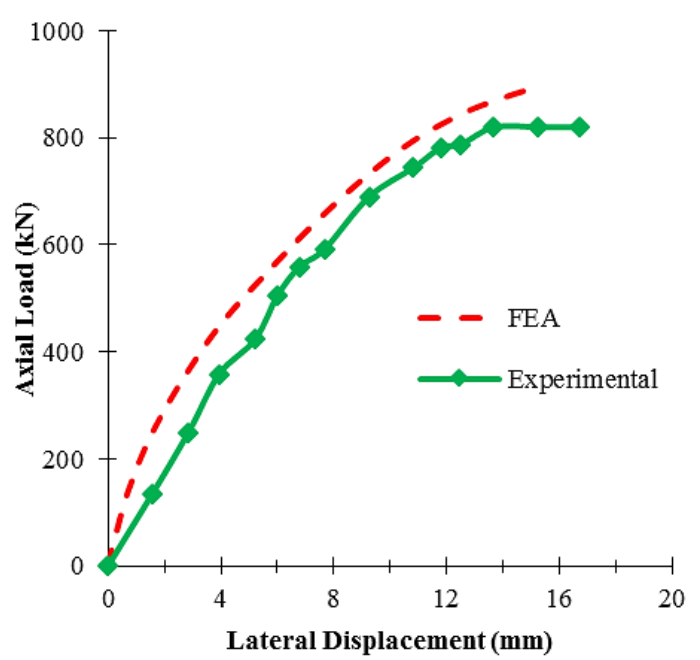

Figure 20. Comparison of predicted result with test data for the column FC35-2

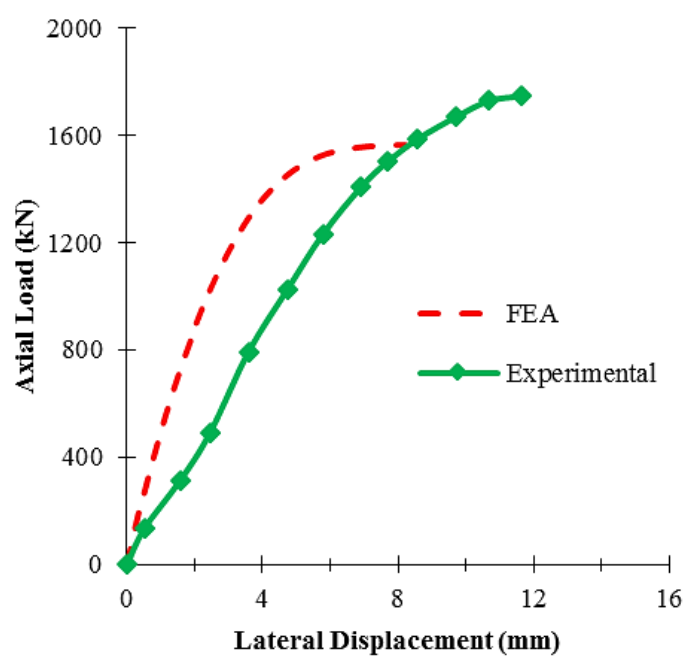

Figure 21. Comparison of predicted result with test data for the column PC10-1

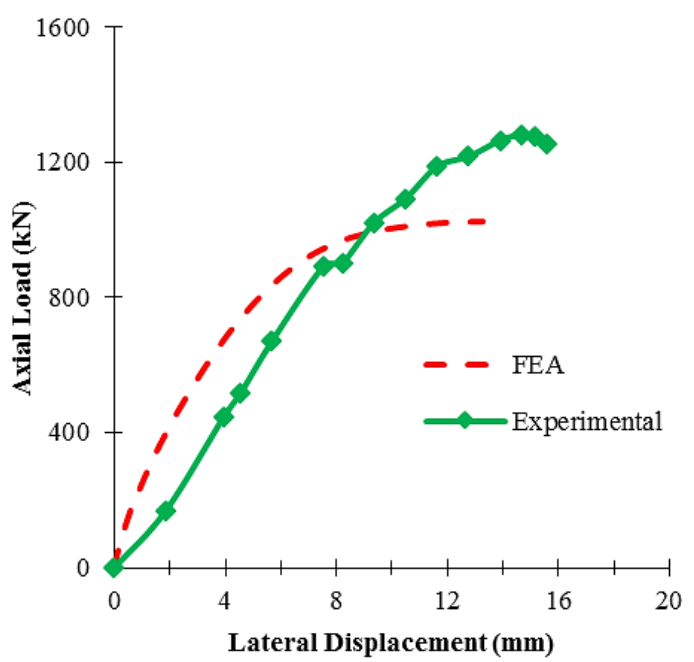

Figure 22. Comparison of predicted result with test data for the column PC20-1 


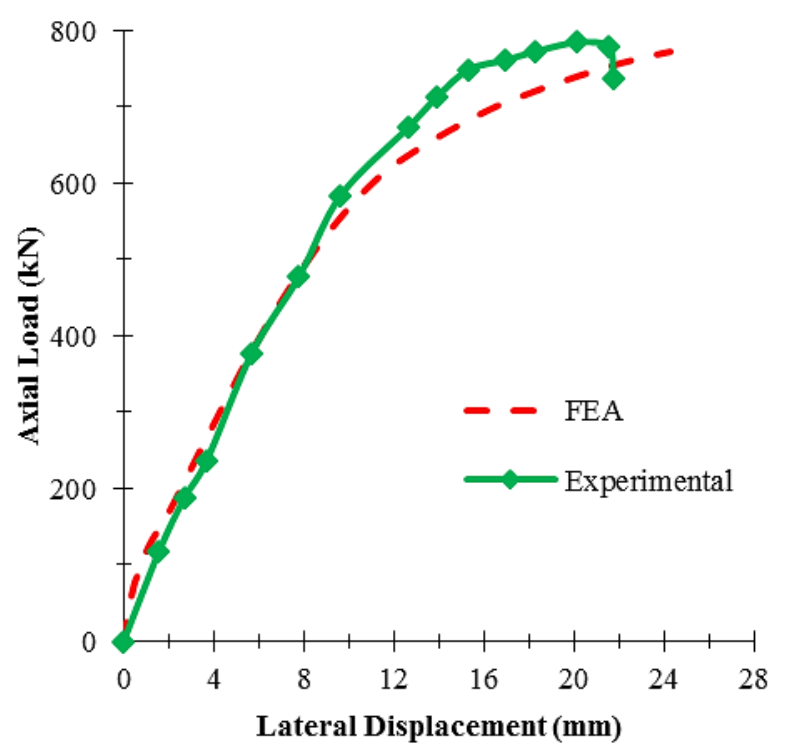

Figure 23. Comparison of predicted result with test data for the column PC35-1

As shown in Figures 15-23, FE analysis results could accurately predict the maximum load and lateral displacement at the mid-height for columns under eccentric loading. Particularly, no significant difference was observed between the analysis results and the test results in spite of assuming perfect bonding between the concrete and the FRP wrap. Thus, it is confirmed that slippage does not occur between the reactive powder concrete and the FRP wrap during the testing. Finally, reasonable agreement was found with respect to the initial slope of the axial load-lateral displacement curve although the proposed discrete finite element model could present a slightly stiffer behavior in some cases. These small differences between finite element analysis results and experimental test results in terms of stiffness behavior observed in some cases can be related to some factors such as the difficulties in reproducing the true boundary conditions of the experimental models or may occur when the modified Kent-Park model is used because of a slight discrepancy between the experimental results of RPC under uniaxial compression to those obtained from modified Kent-Park model.

Regarding the specimen PC20-1, the axial load was lower than the test result although good agreement was reported in term of the lateral displacement response, which may related to a variation in the actual mechanical properties of reactive powder concrete, and/or FRP composites.

Furthermore, the differences of finite element analysis results were small, compared to those obtained from the experimental tests in various eccentricities of the load and concrete compressive strength. In other words, the numerical approach can be used to model the FRP confined RPC columns subjected to compressive concentric and eccentric loading.

Table 4 contrasts the differences of peak loads of finite element analysis and test results for the confined RPC columns. As shown, the predicted loads using finite element analysis is considerably close to the experimental results. In addition, the mean of the ratio of the predicted load to the experimental load, as well as its standard deviation are in a proper range.

Table 4. Comparison of FE modeling results and experimental values taken

\begin{tabular}{cccc}
\hline Column & $\begin{array}{c}\text { Experimental Peak Load- } \\
\text { KN }\end{array}$ & $\begin{array}{c}\text { Predicted Peak } \\
\text { Load-KN }\end{array}$ & Predicted / Experimental \\
\hline FC0 & 2510 & 2475 & 0.986 \\
FC0-1 & 2971 & 2978 & 1 \\
FC0-2 & 2993 & 2960 & 0.988 \\
FC10-1 & 2221 & 2002 & 0.901 \\
FC10-2 & 1912 & 1891 & 0.989 \\
FC20-1 & 1357 & 1293 & 0.952 \\
FC20-2 & 1367 & 1253 & 0.916 \\
FC35-1 & 714 & 720 & 1.008 \\
FC35-2 & 833 & 892 & 1.07 \\
\hline
\end{tabular}


Table 4. Comparison of FE modeling results and experimental values taken (cont.)

\begin{tabular}{cccc}
\hline Column & $\begin{array}{c}\text { Experimental Peak Load- } \\
\text { KN }\end{array}$ & $\begin{array}{c}\text { Predicted Peak } \\
\text { Load-KN }\end{array}$ & Predicted / Experimental \\
\hline PC0-1 & 2571 & 2565 & 0.997 \\
PC0-2 & 2495 & 2565 & 1.02 \\
PC10-1 & 1756 & 1565 & 0.89 \\
PC20-1 & 1287 & 1024 & 0.8 \\
PC35-1 & 773 & 772 & 0.998 \\
\hline \multicolumn{4}{c}{ Mean } \\
\end{tabular}

It is worth noting that time analysis does not exceed from 5 seconds for all the analyzed data, which indicates that the proposed model is capable of providing highly satisfactory predictions and useful for efficient applications in practical engineering projects.

\section{CONCLUSIONS}

The features and deficiencies of the proposed existing models for predicting the behavior of FRP confined concrete columns subjected to concentric and eccentric loading have been discussed in some studies. However, the present study proposed an effective finite element model based on discrete finite element modeling approach to simulate the behavior of reactive powder concrete columns confined by fiber reinforced polymer wrapping subjected to compressive concentric and eccentric load. A comparison study was conducted among six stress-strain models in order to find a simple stressstrain model to predict the compressive behavior of RPC accurately and reliably, which can avoid many of mathematic and large parameters. Finally, the proposed finite element model was verified through comparing available experimental test results and the numerically predicted response results. Based on the nonlinear finite element analysis, the following primary conclusions were drawn:

1. The results obtained from the proposed model are almost in close agreement with those with the experimental data. Based on the results, the proposed model can properly predict the behavior of FRP confined RPC columns under compressive loading with different eccentricities.

2. The ratio of the experimental to predicted peak compressive load varies between 0.8 and 1.07. The mean ratio is $97 \%$ and standard deviation is $6 \%$. All these indicate that the proposed model can provide highly satisfactory predictions, especially in terms of the peak compressive loading.

3. As appeared in the material modeling phase of finite element procedure, it is easy to obtain material parameters for describing the constitutive behavior of RPC and FRP.

4. By taking advantage of the proposed numerical process in the present study, computational efforts of nonlinear finite element analysis are numerically efficient, especially due to the small number of nonlinear beam-column elements and degrees of freedom involved.

5. Since a good correlation is observed between the numerical and experimental data, it is believed that the socalled modified Kent-Park model can give an appropriate and accurate prediction of the stress-strain response of RPC in compression.

6. Generally, the proposed model can be used in practicing engineering process to predict the response of FRP confined RPC columns, where the column is subjected to compressive loading with different eccentricities, compared to other simulation methods such as finite element modeling by using 3D solid elements.

7. The OpenSees software seems to be adequate and efficient for modelling the behavior of FRP confined RPC columns in a good agreement and reducing the requirements of computer disk space in the analysis process.

8. Although the proposed model can be used for RPC confined with FRP, the used finite element procedure can be easily extended in future studies to predict the response of concrete columns having different cross-sections confined by different fiber reinforced polymers under different loading conditions.

\section{REFERENCES}

[1] M. A. Haroun, and H. M. Elsanadedy, "Fiber-reinforced plastic jackets for ductility enhancement of reinforced concrete bridge columns with poor lap-splice detailing,” J. Bridge. Eng. ASCE., vol. 10, pp. 749-757, 2005. 
[2] H. M. Elsanadedy, Y. A. Al-Salloum, H. Abbas, and S. H. Alsayed, "Prediction of strength parameters of FRP-confined concrete," Composites. Part B: Eng., vol. 43, pp. 228-239, 2012.

[3] R. El-Hacha, and K. Abdelrahman, "Slenderness effect of circular concrete specimens confined with SFRP sheets," Composites. Part B: Eng.,vol. 44, pp. 152-166, 2013.

[4] M. F. M. Fahmy, and Z. Wu, "Evaluating and proposing models of circular concrete columns confined with different FRP composites," Composites. Part B: Eng.,vol. 41, pp. 199-213, 2010.

[5] R. Sause, K. A. Harries, S. L. Walkup, S. Pessiki, and J. Ricles, "Flexural behavior of concrete columns retrofitted with carbon fiber-reinforced polymer jackets," ACI Struct. J.,vol. 101, no. 5, pp. 708-716, 2004.

[6] P. Richard, and M. Cheyrezy, "Reactive powder concrete with high ductility and 200-800 MPa compressive strength," In: Proceedings of the V. Mohan Malhotra symposium, ACI SP-144, San Francisco, CA, pp. 507-518, 1994.

[7] P. Richard, and M. H. Cheyrezy, "Composition of reactive powder concrete," Cem. Concr. Res., vol. 25, no. 7, pp. 1501-1511, 1996.

[8] J. Dugat, N. Roux, and G. Bernier, "Mechanical properties of reactive powder concretes,” Mater. Struct., vol. 29, pp. 233-240, 1996.

[9] O. Bayard, and O. Plé, "Fracture mechanics of reactive powder concrete: Material modeling and experimental investigations," Eng. Fract. Mech.,vol. 70, no. 7-8, pp. 839-851, 2003.

[10] J. C. M. Ho, J. Y. K. Lam, and A. K. H. Kwan, "Effectiveness of adding confinement for ductility improvement of highstrengrh concrete columns," Eng Struct., vol. 32, pp. 714-725, 2010.

[11] B. Doran, H. O. Koksal, and T. Turgay, "Nonlinear finite element modeling of rectangular/square concrete columns confined with FRP," Mater. Des., vol. 30, no. 8, pp. 3066-3075, 2009.

[12] T. Yu, J. G. Teng, Y. L. Wong, and S. L. Dong, "Finite element modeling of confined concrete-I: Drucker-prager type plasticity model," Eng. Struct., vol. 32, no. 3, pp. 665-679, 2010.

[13] D. Mostofinejad, and H. Saadatmand, "A procedure for predicting the behavior of FRP confined concrete using the FE method," Sci. Iran. Trans A: Civ. Eng., vol. 17, no. 6, pp. 471-481, 2010.

[14] A. Vulcano, "Macroscopic modeling for nonlinear analysis of RC structural walls," In: Fajfar P, Krawinkler H, editor, Nonlinear seismic analysis and design of reinforced concrete buildings. Bled, Slovenia, Elsivier, pp. 211-225, 1992.

[15] E. Spacone, F. C. Filippou, and E. F. Taucer, "Fiber beam-column model for non-linear analysis of RC frames: Part I. formulation," Earthquake. Eng. Struct. Dyn., vol. 25, pp. 711-725, 1996.

[16] K. J. Bathe, and A. P. Cimento, "Some practical procedure for the solution of nonlinear finite element equations," Comput. Methods Appl. Mech. Eng., vol. 22, pp. 59-85, 1980.

[17] E. F. Taucer, E. Spacone, and F. C. Filippou, "A fiber beam-column element for seismic response analysis of reinforced concrete structures," EERC Report 91/17, Earthquake Engineering Research Center, University of California, Berkeley, USA, 1991.

[18] F. C. Filippou, A. D'Ambrisi, and A. Issa, "Nonlinear static and dynamic analysis of reinforced concrete subassemblages," EERC Report 92/08, Earthquake Eng Research Center, University of California, Berkeley USA, 1992.

[19] H. Dabbagh, and S. J. Foster, "A smeared-fixed crack model for FE analysis of RC membranes incorporating aggregate interlock," Adv. Struct. Eng., vol. 9, no. 1, pp. 91-102, 2006.

[20] S. Popovics, “A review of stress-strain relationships for concrete," ACI J., vol. 67, no. 3, pp. 243-248, 1970.

[21] P. Desay, and S. Krishnan, "Equation for the stress-strain curve of concrete," ACI J., vol. 61, no. 3, pp. 345-350, 1964.

[22] D. J. Carreira, and K. H. Chu, "Stress-strain relationship for plain concrete in compression," ACI J., vol. 82, no. 72, pp. $797-$ 804, 1985.

[23] R. Park, M. J. N. Priestley, and W. D. Gill, "Ductility of square-confined concrete columns," J. Struct. Eng. ASCE., vol. 108, no. 4, pp. 929-950, 1982.

[24] G. M. Smith, and L. E. Young, "Ultimate flexural analysis based on stress-strain curve of cylinders," ACI J., vol. 53, no. 6, pp. 597-610, 1965.

[25] C. E. Todeschini, A. C. Bianchini, and C. E. Kesler, "Behavior of concrete columns reinforced with high strength steels," $A C I$ J., vol. 61, no. 6, pp. 701-716, 1964.

[26] S. L. Prabha, J. K. Dattatreya, M. Neelamegam, and M. V. Seshagiri Rao, "Study on stress-strain properties of reactive powder concrete under uniaxial compression,” Int. J. of Eng Sci. Technol., vol. 2, no. 11, pp. 6408-6416, 2010.

[27] M. Ipek, K. Yilmaz, M. Sumer, and M. Saribiyik, "Effect of pre-setting pressure applied to mechanical behaviours of reactive powder concrete during setting phase," Constr. Build. Mater., vol. 25, pp. 61-68, 2011.

[28] W. X. Li, X. L. Liang, S. T. Zao, and J. Wang, "Study on tunnel lining with reactive powder concrete shotcrete in soft rock strata," Chin. J. of Rock Mech. Eng., vol. 24, no. 2, pp. 5505-5508, 2005. [In Chinese]

[29] S. Zihui, "Mechanical properties and damage analysis of reactive powder concrete with different steel fiber under uniaxial compressive load," MSc Thesis, Beijing Jiaotong University, Beijing, China, 2007. [In Chinese]

[30] M. M. Attard, and S. Setunge, "Stress-strain relationship of confined and unconfined concrete," ACI Mater. J., vol. 93, no. 5, pp. 432-444, 1996.

[31] M. K. M. Reddiar, "Stress-strain model of unconfined and confined concrete and stress-block parameters," MSc Thesis, Texas A\&M University, Texas, USA, 2009. 
[32] C. Yalcin, and M. Saatcioglu, "Inelastic analysis of reinforced concrete columns," Comput. Struct., vol. 77, pp. 539-555, 2000.

[33] A. E. Assan, Nonlinear analysis of reinforced concrete cylindrical shells," Comput. Struct., vol. 80, pp. 2177-2184, 2002.

[34] P. Martinelli, and F. C. Filippou, "Simulation of the shaking table test of a seven-story shear wall building," Earthquake. Eng. Struct. Dyn., vol. 38, pp. 587-607, 2009.

[35] R. Al-Amery, and R. Al-Mahaidi, "Numerical analysis of multilayered CFRP retrofitted RC beams with partial interaction," Compos. Struct., vol. 75, pp. 479-488, 2006.

[36] N. Navidpour, "Non-linear finite element analysis and parametric investigation of low-rise reinforced concrete shear walls," PhD Thesis, University of Otawa, Ottawa, Canada, 1999.

[37] S. Mazzoni, F. McKenna, M. H. Scott, and G. L. Fenves, "OpenSees command language manual,” Berkeley (USA), Pacific Earthquake Eng. Research Center. University of California, USA, 2007.

[38] A. R. Malik, and S. J. Foster, "Carbon fiber-reinforced polymer confined reactive powder concrete columns-experimental investigation,” ACI Struct. J., vol. 107, no. 3, pp. 263-271, 2010.

[39] A. R. Malik, "An investigation into the behaviour of reactive powder concrete columns," PhD Thesis, University of New South Wales, Sydney, Australia, 2007. 